\title{
Skills Sets for Workforce in the 4th Industrial Revolution: Expectation from Authorities and Industrial Players
}

\author{
Aizuddin Saari ${ }^{1}$, Mohamad Sattar Rasul ${ }^{*}$, Ruhizan Mohamad Yasin ${ }^{1}$, Rose \\ Amnah Abd Rauf ${ }^{2}$, Zool Hilmi Mohamed Ashari ${ }^{3}$, Diaz Pranita ${ }^{4}$
}

${ }^{1}$ Faculty of Education,

Universiti Kebangsaan Malaysia, 43600 UKM Bangi, Selangor, MALAYSIA

${ }^{2}$ Faculty of Education,

Universiti Malaya, 50603 Kuala Lumpur, MALAYSIA

${ }^{3}$ Department of Skills Development, Ministry of Human Resources (MoHR), 62502 Putrajaya, MALAYSIA

${ }^{4}$ Higher Vocational Education,

Universitas Indonesia, INDONESIA

*Corresponding Author

DOI: https://doi.org/10.30880/jtet.2021.13.02.001

Received 30 ${ }^{\text {th }}$ December 2020; Accepted 19 ${ }^{\text {th }}$ April 2021; Available online 30 $0^{\text {th }}$ June 2021

\begin{abstract}
Klaus Schwab, founder and the executive chairman of the World Economic Forum announced the arrival of a new revolution, the Fourth Industrial Revolution (4IR), characterized by a combination of technology that changes the line between fields and is driven by three mega trends of digital, physical systems and biological along with ways that will change people's lives and the job market in the future. The arrival of the 4IR needs a further action on identifying industry trends, job demands and possibilities that may arise in parallel with this revolution especially to strengthening potential for skills development in line with 4IR. The skill sets required in both existing and new occupations will change and transform on how people work. The aim of the article is, to understand, as well as between developed and emerging markets, the employment, skills and education concerns of individuals. A qualitative research design with a focus group was used to collect data for this study. The focus group method entails focus group discussions on the aspect of strengthening human potential for skills development in line with 4IR, involving stakeholders members from the competence body which is Department of Skills Development (DSD) Malaysia, industry players from Industry Lead Body (ILB) appointed by DSD of various industry and an academician from the different TVET institutions. The findings showed four strategic aspect that can be used as a guideline to develop the skills set for 4IR which are empowering digital skills, proficient in using high impact technology, entrepreneurial mindset and lastly skilled workers with a combination of technical skills and soft skills.
\end{abstract}

Keywords: Industrial revolution, potential, skills, skill sets, focus group discussion

\section{Introduction}

Fourth industrial revolution (4IR) is an improvement and effort to resolve issues in the future when industrial activities operate fully automated with the help of technology (Schwab, 2016). Shank (2016) stated about radical changes in employment mentioned in the books of The Second Machine Age and Race Against the Machine and the effects of a 
variety of technologies being used in diverse fields, such as manufacturing, clerical and retail work, law, financial services, education, and medicine. How they are changing work and employment prospects and our readiness to ride the 4IR wave are being studied by the government and industrial organizations in Malaysia (Ahmad, 2017). The Malaysian government through Department of Skill Development (DSD) is very committed to achieve this agenda. Department of Skills Development (DSD), which is formerly known as the National Vocational Training Council (MLVK) is a Department under the Ministry of Human Resources which was established in $2^{\text {nd }}$ May 1989.

The name later was changed to JPK after the National Skills Development Act 2006 (Act 652) came into force on 1st September 2006. The purpose of its establishment with the objective to coordinate and regulate the implementation of skills training to produce K-Workers for the purpose of employment and recognition at national and international levels and do research to develop job competency standards and expertise to continuously improve the quality of skilled human resources who can contribute to the economic growth of the country. The existence of industry 4.0 is a paradigm that has shown the adaptation of machines and the automatic adjustment of their tasks to meet human interests that can be met through the intermediation of several systems namely Cyber-Physical System (CPS) and also Industry 4.0 itself. Transformation development is often associated with advances in science and technology. The industry players from Industry Lead Body (ILB) appointed under DSD of various industry like manufacturing, oil and gas, pharmaceutical, finance and many more play main role to make sure national agenda can be achieved.

The Fourth Industrial Revolution (4IR) is an evolution from the previous industrial revolution that is more advanced and adopted by developed countries. In the final phase to achieve the status of a developed country, Malaysia needs world-class skilled human capital through TVET focus areas. Experts indicate that part of the reason is that our skills are not keeping up with technological advances. The advent of the Fourth Industrial Revolution is leading us into a period of great transformation. The technologies that surround us will alter all aspects of life. Adznir (2017) said that the skill sets required in both old, new occupations will change in most industries, and transform how and where people work. It may also affect female and male workers differently and transform the dynamics of the industry gender gap. The objective of this topic is to understand globally, as well as between developed and emerging markets, the employment, skills and education concerns of individuals. In addition to that, this study also intends to identify the opportunity to improve the female and male workers' learning skills in the areas of teamwork, communications, decision-making, negotiation, conflict resolution and organizational development and change, including how to create more innovative learning for Skills Development in 4IR.

This Industrial 4.0 phenomenon can be seen in terms of education and job skills in the industry. It is a need to foster self-potential to provide an exciting opportunity to transform society for the better (Xing \& Marwala, 2017). However, among the effects expressed by some researchers are the loss of work due to the process of automation and mastery of IT, problem-solving and especially to some less knowledgeable society which is needed to strengthen a potential and to handle a wide range of complex information in the digital age. Cyprus Pedagogical Institute (2016) also mentioned that it is crucial to understand the global community as well as meet the needs of the 21 st-century job market which includes the ability to think critically, take initiative, use digital tools, solve problems and work together in a group. The Fourth Industrial Revolution, characterised by the fusion of physical, digital, and biological technologies, will have profound social and economic consequences and the demand for skilled labour, especially in the technology sector continues to be critical even though the country has a high labour shortage problem among young and highly educated people (Soh, 2021). This shows that the needs to embrace skills sets for the industrial revolution must start from now. Thus this research aims at developing skilled workers' skills set to be able to participate in the 4th Industrial Revolution as competent workers.

\section{Methodology}

\subsection{Research Design}

A qualitative research design within a focus group discussion (FGD) is used in the data collection procedures for this study. The FGD entails small groups of participants contributing to moderate group discussions on a certain topic (Bloor et al. 2001). This method is an economical, fast, and efficient method for obtaining data from multiple participants (Krueger \& Casey, 2000). In this study, the focus groups assisted in identifying the most relevant issues to be discussed during the discussion session.

\subsubsection{Expert Participants/ Panels}

A total of 20 individuals participated in the focus groups session which consists of the competence body which is the Department of Skills Development (DSD) Malaysia, industry players from Industry Lead Body (ILB) appointed by DSD of various industry and an academician from different TVET institutions. All the participants agreed and signed a consent letter to participate in the discussion. The DSD has also taken the initiative to introduce the Industrial Lead Bodies (ILB) that are involved in ensuring the National Occupational Skills Standard (NOSS) is developed in tandem with the respective industry's standards and requirements. This move will also forge more relationships between the DSD and the industry to inline the skills program development and enable double certification with cooperative Licensing 
Bodies. The DSD has set up Industry Lead Bodies (ILB) which represents specific industry sectors as strategic partners in determining the needs for the development of skilled workers, enhancing the acceptance of the skills-testing industry and becoming the driver of skilled worker development and training. Among ILB functions is the analysis of relevant occupations within specific industries, development of new NOSS and periodic review of existing NOSS. The role and responsibility of ILB in this research as a panel in the FGD are to identify industry trends, job demands and possibilities that may arise in parallel with this revolution especially to strengthening the potential for skills development in line with 4IR.

\subsubsection{Data Collection Procedure}

All participants of this study were actively involved in the discussion. Participants were divided into groups and also given a moderator who leads the discussion and two rapporteurs who worked to help, record the conversation and subsequently record the important content of the discussion. The discussion lasted for four hours, and each participant was given the opportunity to voice out their opinions and views. The instrument used in this study was a set of questions based on the objectives of this study.

\subsubsection{Interview Protocol}

The questions were checked and confirmed by the expert from Universiti Kebangsaan Malaysia and DSD. All the question were:(1)What type of skills you think is relevant for the 4th Industrial Revolution workforce?; (2)What industry sectors you expect to emerge or grow in the forthcoming of the 4th Industrial Revolution?; (3)What industry sectors you expect will be disrupted by the forthcoming of the 4th Industrial Revolution?; (4)How relevant and prepared is our TVET system and training skills provider for the 4th Industrial Revolution?; (5)How can your organization helps to develop the skills sets required together with the institution?; (6)What human resource skills does your organization needs to develop in preparation for the 4th Industrial Revolution?; (7) What kind of IT challenges that TVET providers will face keeping up with the 4th industrial Revolution? The data from the focus group session was collected using recording audio and were transcribed and analyzed using thematic analysis to identify the theme and code aided by data analysis software, ATLAS.ti.

\subsection{Data Analysis Procedure}

In this study, researchers used the theme analysis method to analyse the collected interview data. Theme analysis is one of the methods of identifying, analyzing and reporting patterns (themes) in qualitative data (Zhan et al., 2021). Data between study participants and data from various sources will be compared to determine appropriate categories and themes. This analysis process was done using Atlas.ti software to manage and generate code for the theme. The theme table is not determined from the beginning of the study, however, the data analysis process started from open coding to get as many themes and categories to be associated with the study phenomenon, followed by axial coding and selective coding. Therefore, managing and categorizing the data is the most important component throughout the study from the beginning to the conclusion stage of the study findings (Merriam, 2009). This analysis minimally organizes and describes the set data in detail. Hence, for this study, it refers to the findings and emergence of themes derived from the interview results. Theme determination can also be determined using Atlas.ti software.

Atlas.ti software has been developed specifically for research based on the Grounded Theory approach (Silverman, 2000). ATLAS.ti is a qualitative data analysis software program that allows any researcher to manage, encode, analyze, and extract processed data in a variety of simple methods, thus making the researcher's data easier to understand (Abdullah, 2015). According to Gibbs (2007), the implementation of qualitative analysis requires a large amount of carefully and complex managed text, code, memos and notes. ATLAS.ti can help researchers to "explore hidden phenomena in data", by allowing researchers to collect large amounts of data, including interview transcripts, PDFs, Microsoft Word documents, Html, images, and even audio and video recordings. The data can then be coded and analyzed for themes and other information. In the context of this study, researchers used ATLAS.ti as a tool to easily manage data that were collected from the analysis of circuit surveys and interview data that were conducted with experts.

\section{Results}

The results from the focus group discussions have shown that there were four strategic aspects that need to be considered by the Department of Skills Development (DSD), Ministry of Human Resources Malaysia in strengthening and fostering the human potential for skills development in the 4th Industrial Revolution (Figure 1) which are empowering digital skills, proficient in using high technology, entrepreneurial mindset and combination of technical and soft skills. 


\subsection{Proficient in Using High Technology}

Three aspects that emerged from the discussion involving being proficient in using high technology, which are capable of using impactful technology, re-skilling and up-skilling employee's technology skills and supporting systems to support the technology.

\subsubsection{Capable in Using Impactful Technology}

Capable in using impactful technology is one of the important aspects mentioned by the panels. Comments made by the panels were all about how they introduce one technology based on not just by looking at the technology itself but the impacts made by the technology to the existing human capital and productivity, as mentioned by the panel P2;

"we want to introduce high-tech technology, we should not just looking for those is younger generation and marginalize group in the existing human capital. we have to look into that aspect by not just accepting the technology although it is good in production, we need to evaluate whether it actually benefits the overall organisation.",

\subsubsection{Re-skilling and Up-Skilling Employee's Technology Skills}

Re-skilling and up-skilling employee's technology skills is another important aspect in nowadays industries. In the case of some organizations, re-skilling and up-skilling employees are necessary because currently, the industry is getting more competitive. Hence, due to this, whether you like it or not, we have to improve our productivity and the technology that are taking place as well. Due to this, they have to improve their technology by all means. We have to look at how to develop our trainer, so the training programs should be progressively strong as well to keep in line with fourth industrial revolution in order to produce quality students.

\subsubsection{Supporting Systems to Support the Technology}

Supporting systems to support the technology aspect is not less important from the other two. It is stated clearly in which said by the panel P4 as;

"we are not technology creator or inter-venter all this while we are user. We buy technology
to develop, we use it but we don't have supporting to support technology that we buy for
Malaysia..."

This shows that we clearly need to either have our own supporting technology or creating our own to uphold and sustain the existing system. We could see how developed countries keep being excited to design and shape up brand-new supporting technologies to encourage their country, not only in the economic aspect, but also for people to keep up with the environment. As a developing country, we need to catch up to create our own supporting technologies so it can suit to our country's environment.

\subsection{Entrepreneurial Mindset}

Entrepreneurial mindset can be divided into three major aspects which are nurture and enhance survivor skills in entrepreneurial, to embed entrepreneurial interest in curriculum, and competency in order to nurture entrepreneurship. Nurturing and enhancing survival skills in entrepreneurial can be defined as to let ourselves to learn and hone the skills in order to thrive in today's business world, and we need to be able to adapt and adjust those skills to our own surroundings. Panel P9 once said;

"Another module to be consider is entrepreneur. Actually, we have a textile industry to
introduced entrepreneurship program for the industry which I actually two of my company
attached to the program. Now is how they think like a businessman in the company. So how
they save the company cost, how they innovate new team, how they cut processes, how they
improve processes, so that path of entrepreneurship..."

Another aspect that was highlighted in the discussion is to embed the entrepreneurial interest in curriculum.

"So preparation of the individual. And one think that I know it the DSD already started to put their elements of entrepreneurship skills in one of the competencies especially in level 4 and level 5. Okay so we ready put it in the curriculum itself. To embed entrepreneurial interest in curriculum 
As for technical discipline, students are interested in creating their own organizations after graduation, however, they seem to be left with no guide although in many cases, they are the originators of product ideas. In Malaysia, there is a growing concern that technical students do not have sufficient entrepreneurial skills to venture in business particularly running small and medium enterprise (SME) set-ups. There are comments that these students have narrow business perspectives, less flexible to branch in other working areas and foresee themselves as only job seekers and not job creators. Panel P1 said that,

" Entrepreneurship is always talking about challenge. I think we should explore this a entrepreneurship curriculum to the skills people. Perhaps they can combine and connect their skills, their knowledge, and also their attitude. Multi-disciplined or competency in order to nurture entrepreneurial'"

\subsection{Empowering Digital Skills}

The next aspect that was being pulled up by the panelist during the discussion is empowering digital skills. Four aspects have emerged from this discussion which are training course through online, digital skills to deliver knowledge, skills on information and communication technology (ICT), and digitalization of TVET. The first important point that came up during the discussion was training course through online. There are a lot of online platforms that provide training courses, either the free courses or otherwise. Panel P3 said that;

“.... and as of today a lot of the training also offered through online courses if they want to upgrade themselves. They sign up with course to get the certificate, we see more and more that kind of training..."

An online course is the delivery of a series of lessons on a web browser or mobile device, which can be accessed anytime and at any place. It is designed as an online environment for convenient learning asynchronously. Those courses might offer certificate such as participation certificate, and also competency certificate. This will increase the individual skills and if chances are taken seriously, there are a lot to learn in online platforms.

The next aspect that was discussed by the panelist is digital skills to deliver knowledge for new generation. Experience is what differentiate the current personnel with the new generations. Delivering knowledge is very crucial to make sure the experience in terms of knowledge will last. A panelist, P10 said;

"Can I use the word of digital skills? Yes, we want to use digital but what happen now, we may have different kinds of generations who are being the instructors or educators, maybe baby boomers and also generations text, ability of them, they may not have that kind of digital skills. It's hard for them to influence the new generations..."

Digital skills to deliver knowledge can be said as the ability to use digital devices, communication applications, and networks to access and manage information to be hand over to the newcomers. As we know, the new generations mostly depending on digital devices to make things happen and in getting new information. That makes the skill of using digital skill to deliver knowledge is so crucial right now. We might say that the digital communication is currently the best business to invest on.

Not being left out in the discussion is another element which is skills on information and communication technology (ICT). In this era of globalization, we know that there are a lot of applications being used nowadays as a communication platform. Every social media has their own messenger system, while others using application that is interconnected by internet, both are dedicated for communicate to each other. Panelist P5 said that;

$$
\begin{aligned}
& \text { "... when u didn't understand the digital, it's hard for you even to e-mail to your subordinate } \\
& \text { or your counter-part from overseas, they will get different perception from what you want..." }
\end{aligned}
$$

As the world goes on, everything has been digitalized and not being able to communicate through the digitalized environment is a big no. The world keep evolving and demanding us to follow its path. To be compatible to communicate through digitalized world is a must, so that we can keep moving forward, together with the industrial revolution that we face right now. The last aspect that being discuss is the digitalization of TVET. A panel, P6 said that;

“...But the more digitalization and industrial revolution will happen, the more the skills on jobs, let say. Professions become more academic like you said, ICT and so on. And this is also a chance to raise maybe the image of TVET through digitalization and industry 4.0..."

The digital workforce has developed many competencies in the course of their interactions with technology that may be leveraged at work and also encourage workers to master the latest technologies or digital competencies in order to keep in a competitive position in various industries. 


\subsection{Skilled Workers with a Combination of Technical Skills and Soft Skills}

The result of discussion skilled workers with a combination of technical skills and soft skills has three aspects, which are balance in technical and soft skills, enhance soft skills to deliver technical skills and curriculum empowerment to enhance both skills. One of the important aspects mentioned by the panels is balance in technical and soft skills. One comment made by the panel, P5 is that; "to me, the things must be exist together. Not to say merge and one merges without both.
Actually, both are important. Because in our educational system itself, it almost $70 \%$ are not
interested in academic. They are more towards skills, you know. The excellent people only
$30 \%$ who are moving toward academics. But, the rest, where are they? In the vocational, this
is what TVET all about"

"in our passion to supply technical skills that can meet the challenges of industry 4.0, we shouldn't't be forgetting about our basic skills. Humanizing skills, humanizing aspect of our workers"

This clearly indicates that it is important to have skilled workers with a combination of technical skills and soft skills. Another aspect that emerged from the discussion is to enhance soft skills to deliver technical skills. Technical knowledge and skills alone have a short life span and job specific, thus may not be transferable to other trades. Each employee has to have the desire to upgrade their skills if they want to continue contributing to the progress of the organization to enhance or to help deliver their technical skills. As for example, students from Institut Latihan Perindustrian (ILP) usually are good technically, have good TVET knowledge on how to run software and do the system. However, they do not know how to start, how to be in the market, to cooperate well with other companies, and the ways to be involved and be a player in the market or industry. Hence, this technical knowledge alone is not helping, right from the beginning. Thus, in term of numbers, the produce of skilled workers are a lot but not balanced in terms of soft skills. Just like a lawyer, you produce a good lawyer to fight but the end of the day when they intend to open lawyer firm, they would not know the way to go about it.

The last aspect of this discussion is curriculum empowerment to enhance both skills. There is now more pressure on academic institutions to enhance both technical skills and soft skills of their students. Thus, the learning institution needs to look at back to the syllabus, the process and the methodology on how to bring their students moving forward in the forthcoming revolution. Also, the institution needs to provide a clear career path or framework guidance for students to make sure they get the clear direction after graduated. With well-planned training programs, it is possible to tune, shape and develop creativity and soft skills among all students. This is important to make sure the produce of skilled workers with a combination of technical skills and soft skills as a need to fulfil fourth industrial revolution.

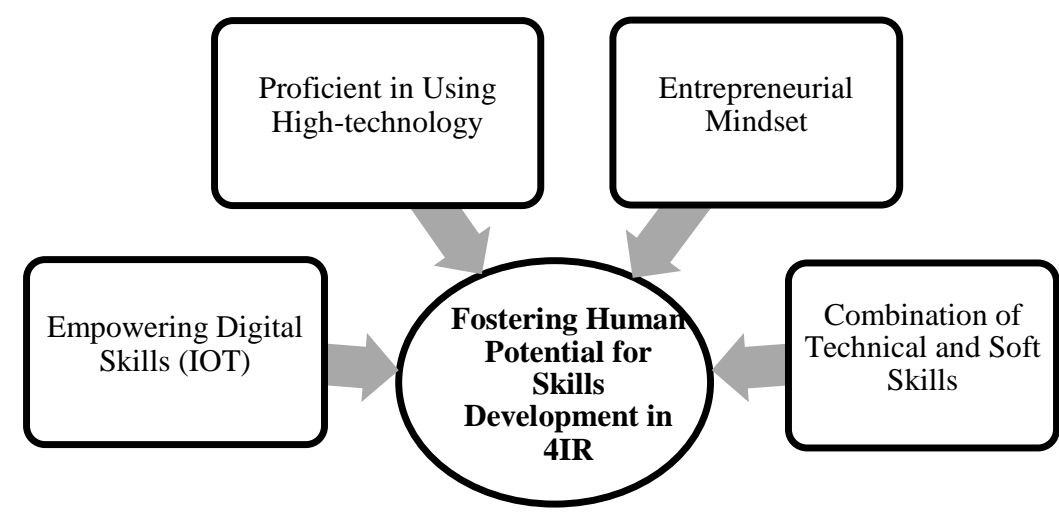

Fig. 1 - Four strategic aspects for Skill Workers' skills set development in 4th Industrial

\section{Discussion}

From the data analysis, there are 4 strategic aspects that can be used as a guideline for the Department of Skills Development with collaboration institutions and industry to strengthen human potential for Skill Workers' skills set development in line with the fourth industrial revolution. The analysis has shown that being proficient in using high technology has three aspects, which are capable of using impactful technology, re-skilling and up-skilling employee's technology skills and supporting systems to support technology. Today's era is a fully digital era in every sector, hence there is a need to move parallel and being proficient in using high technology to deliver, communicate to each role players 
and vice versa (Tejasvee et al., 2021). Globalization and the intensive use of information and communication of high technology have led to the emergence of a new economy (Boutin et al., 2009) which is a knowledge and idea-based economy where the keys to job creation and higher standards of living are innovative ideas and technology embedded in services and manufactured products. This was also supported by previous study which have found that employees who understand and can leverage the power high technology will also be valuable to organizations (Kumar et al. 2016). The role of the employees together with the role of the technology can lead to advanced learning results (Sharma and Jain, 2013). Taken together, these findings suggested that Department of Skills Development can create self-development programs and enhance talent for employees such as re-skilling, up-skilling and up scaling. Also, it can help to implement Industrial Attachment and Industrial Exposure Programs to instructors in the industry. Reduce dependency on the foreign expertise. The need for sharing knowledge between research institutions and industry has become increasingly evident in recent years (Pusavec et al., 2010). So, DSD are suggested to organize any programs that can improve industrial experience of using high technology among workers.

The research clearly indicates the needs of entrepreneurial mindset from three aspects of discussion, which are to embed entrepreneurial interest in curriculum, nurture and enhance survivor skills in entrepreneurial and the last aspect is competency in order to nurture entrepreneurship. Recurring theme in entrepreneurship education over the past decades is that entrepreneurs have what has variously been described as having an "entrepreneurial perspective" (Kuratko, 2005), entrepreneurial "personal capabilities" (Laukkanen, 2000), "entrepreneurial mindset" (Kouakou et al., 2019) and entrepreneurial "human characteristics and traits" (Ali, 2019). Effective career planning involves clearly setting defined career objectives and strategies to achieve them (Gould, 1979; Jackson 2017). In 4IR, the institutions or workplace needs to create a 4.0 Industry Mindset where it is no longer the era to "seek work", but to "create their own career". This is because, in a study done by Kuratko, Hornsby, and McKelvie. (2021), it is shown that arts entrepreneurship education demonstrates that it is not solely focused on enabling person to make money but is far more focused on supporting person to think creatively, reflectively, strategically, and analytically about their creative practices in terms of its output to a wider field than is currently found in creative and performing arts education. Besides that, the DSD and institutions are suggested to provide comprehensive ecosystem to workers or graduates who are interested in becoming entrepreneurs, provide infrastructure, access to entrepreneurial training model, collaboration with training institutions and international organizations and encourage more innovations to be generated.

Next, the discussion revealed upon empowering digital skills and consists of four aspects which are training course through online, digital skills to deliver knowledge, skills on information and communication technology (ICT), and digitalization of TVET. UNESCO (2016) has developed a new strategy for technical and vocational education and training (TVET) 2016-2021, where digital skills and digital technologies are indicated as means to support the transition to green economies and sustainable societies. The digital skills agenda is in rage, and much is being done to encourage young people to realize the importance of this skill in 4IR. The arrival of computing on the curriculum shows that the importance of digital skills is being recognized (Lambert, 2017). Due to the world challenge nowadays and COVID-19 pandemic, there is a need for people to empowering their digital skills to make challenge and obstacle faced to become a great opportunity (Monteiro and Leite, 2021). Thus, DSD are suggested to implement digital literacy enhancement courses such as coding for instructors and students. Furthermore, DSD can also try to implement cyber security surveillance, security assurance, cyber forensics, cryptographic technologies, and security management based on National Occupational Skills Standard (NOSS) requirement. The institutions should encourage students to improve their digital skills by taking online courses. They also should encourage students to master the latest technologies or digital competencies to keep students in a competitive position in various industries. In addition to that, they also need to encourage students to master elements such as communication, critical thinking, collaboration, creativity, problem solving, technical skills, digital skills, social skills and social values.

Results from the study have also shown that skilled workers with a combination of technical skills and soft skills has three aspects, which are having balance in technical and soft skills, enhance soft skills to deliver technical skills and curriculum empowerment to enhance both skills. In this new era, most of the employers need their employees to not only possess technical or hard skills but also generic skills or soft skills to face the new world challenge to sustain and competitive (Sussman, 2021). Employees that possess soft skills will be able to adapt to any working situation and versatile (multi-skilled) suitable with the needs of the current job market (Overtoom 2000; Safarin \& Kamarudin 2004; Ab. Rahim \& Ivan, 2007). Technical knowledge and skill alone have a short life span and job specific, thus may not be transferable to other trades. Each employee has to have the desire to upgrade his or her skills (for example) if he or she is to continue contributing to the progress of the organization (Mazlan et al., 2015). When there was an economic crisis quite recently, many workers lost their jobs entirely through voluntary retirement or forced retirement. The employer retains some, and they however, are required to undergo a retraining to learn new skills and acquire new knowledge.To make today's students and industrial users familiar with the topic and the related challenges, new curricula are necessary (Faller, \& Feldmüller 2015). Develop and implement government policies in education and training to meet the 4IR demand. Re-plan policies to ensure marketability. 


\section{Conclusion}

The findings give insight into the TVET educationist and training centers to give emphasis to the four strategic plans that have been identified as a guideline to develop skills among skill workers in the industries to be able to adapt and give their full competencies in their work. Effort should be focusing more on producing workers that are proficient in using high-impact technology, instilling an entrepreneurial mindset among the skill workers, empowering digital skills through training courses that emphasise the usage and digitalizing work to enable the easy transition towards green economics and sustainable societies. Lastly, it is also crucial in ensuring that skilled workers are balanced with both technical and soft skills. These skills should be presented and mastered in all skill workers so that the workers can cope with the lack of the other and have the motivation and need to find the extra skills needed by their job as the situation in the workplace evolves over time. This study focuses only on identifying the aspects of the skills set that should be developed to prepare for the 4th industrial development. Future research on the specific 'know how' and assessment of these skills should be good to be further investigated.

The fourth industrial revolution (4IR) is the coming together of cyber networks, with physical networks, to create new autonomous systems also known as to be the first sustainable industrial revolution, governments and regulators will need to adapt quickly to the rapidly evolving 4IR landscape and provide the enabling environment, safeguards, investment and oversight to guide the future that is being built. Thus, new skill development for 4IR is one of the initiatives to succeed the 4IR. However, it is needed to strengthening and fostering the human potential for skills development in 4IR. The findings have shown four strategic plans that can be used as a guideline by the Department of Skills Development in order to develop skills for 4IR which are proficient in using high-impact technology, to have an entrepreneurial mindset, empowering digital skills, and lastly was produce skilled workers with a combination of technical skills and soft skill. Further study is needed to make sure these strategies can be used and implemented successfully.

\section{Acknowledgments}

This work was supported in part by Department of Skill Development, Ministry of Human Resources Malaysia, grant number; AKU220, The National University of Malaysia under the Program of STEM and Minda with Grant Code - GG-2019-076

\section{References}

Adznir, M. (2017). A Study of Competencies That Influence Entrepreneur Performance in Retail Business Ventures in Malaysia. Southern Cross University

Ali, I. (2019). Personality traits, individual innovativeness and satisfaction with life, Journal of Innovation \& Knowledge, 4 (1), 38-46, ISSN 2530-7614

Bloor, M., Frankland, J., Thomas, M., and Robson, K. (2001). Focus groups in social research: Introducing qualitative methods, SAGE Publications, Thousand Oaks, CA

Boutin, F., Chinien, C., Moratis, L., \& van Baalen, P. (2009). Changing Workplace Requirements: Implications for Education. In R. Maclean, D. Wilson (eds.), International Handbook of Education for the Changing World of Work, Part II, Section 1, (pp. 81-96), Springer Netherland

Cyprus Pedagogical Institute. (2016). Assessment of Transversal Skills 2020. Retrieved from http://www.ats2020.eu/

Faller, C. \& Feldmüller, D. (2015). Industry 4.0 Learning Factory for regional SMEs. Procedia CIRP, 32(Clf), (pp. 8891). doi:10.1016/j.procir.2015.02.117

Gould, S. (1979). Characteristics of career planners in upwardly mobile occupations. Academy of Management Journal, 22(3), (pp. 539-550). https://doi.org/10.2307/255743

Jackson, D.A. (2017). Using work-integrated learning to enhance career planning among business undergraduates. Australian Journal of Career Development 2017, Vol. 26(3) 153-164. Australian Council for Educational Research 2017. sagepub.co.uk/journalsPermissions.nav DOI:10.1177/1038416217727124

Kouakou, K.K.E., Jiangsu. Akolgo, I.G., \& Tchamekwen, A. M. (2019) Evolution View of Entrepreneurial Mindset Theory, International Journal of Business and Social Science 10 (6), DOI:10.30845/ijbss.v10n6p13

Kumar, A., Bezawada, R., Rishika, R., Janakiraman, R., \& Kannan, P. K. (2016). From social to sale: The effects of firmgenerated content in social media on customer behavior. Journal of Marketing, 80(1), 7-25

Kuratko, D. (2005). The emergence of entrepreneurship education: Development, trends, and challenges. Entrepreneurship Theory and Practice, 29(5), 577-598 
Kuratko, D. F., Hornsby, J. S., \& McKelvie, A. (2021). Entrepreneurial mindset in corporate entrepreneurship: Forms, impediments, and actions for research. Journal of Small Business Management, 1-23, DOI: $10.1080 / 00472778.2021 .1907585$

Krueger, R. A., \& Casey, M. A. (2000). Focus groups: A practical guide for applied researchers (3rd ed.). Thousand Oaks, CA: Sage

Lambert, L. (2017). The Four Challenges of the Fourth Industrial Revolution. Market Mogul. Available online at https://themarketmogul.com/industry-4-0-challenges/?hvid=2Gt2CE [Accessed on 05 June 2019]

Laukkanen, M. (2000). Exploring alternative approaches in high-level entrepreneurship education: Creating micromechanisms for endogenous regional growth. Entrepreneurship \& Regional Development: An International Journal, 12(1), 25-47

Mazlan, A. S., Abd Manaf, Z., Talib, Z. A., Bakar, A. R., \& Mood, N. Z. N. (2015). Technical Vocational Education \& Training (TVET) in Malaysia: Selected Works. Journal of Technical Education and Training, 7(1), 13

Merriam, S. B. (2009). Introduction to qualitative research. Qualitative research in practice: Examples for discussion and analysis, 1(1), 1-17

Monteiro, A., \& Leite, C. (2021). Alfabetizaciones digitales en la educación superior: habilidades, usos, oportunidades y obstáculos para la transformación digital [Digital literacies in higher education: skills, uses, opportunities and obstacles to digital transformation], DOI: 10.6018 / red.438721

Overtoom, C. (2000). Employability skills: An update. ERIC Digest No. 220

Pusavec, F., Kramar, D., Krajnik, P., \& Kopac, J. (2010). Transitioning to sustainable production-part II: evaluation of sustainable machining technologies. Journal of Cleaner Production, 18(12), 1211-1221

Schwab, K. (2016). The Fourth Industrial Revolution: What it means and how to respond. World Economic Forum. Retrieved from https://www.weforum.org/agenda/2016/01/the-fourth-industrial-revolution-what-it-means-and-how-torespond/

Shank, P. (2016). The Fourth Industrial Revolution: What Happens with Employment? Assoc. Talent Development, 1-11

Sharma, M. K., \& Jain, S. (2013). Leadership management: Principles, models and theories. Global Journal of Management and Business Studies, 3(3), 309-318, Research India Publications

Silverman, D. (2000). Analysing talk and text. Handbook of Qualitative Research, 2(0), 821-834

Soh, C., \& Connolly, D. (2021). New frontiers of profit and risk: The Fourth Industrial Revolution's impact on business and human rights. New Political Economy, 26(1), 168-185, DOI: 10.1080/13563467.2020.1723514

Sussman, L. L. (2021). Exploring Non-Technical Knowledge, Skills, and Abilities (KSA) that May Expand the Expectations of the Cyber Workforce. Cybersecurity Skills Journal: Practice and Research, University of Southern Maine

Tejasvee, S., Gahlot, D., Poonia, R., \& Kuri, M. (2021). Digital Learning: A Proficient Digital Learning Technology Beyond to Classroom and Traditional Learning. In Advances in Information Communication Technology and Computing (pp. 303-312). Springer, Singapore

United Nations Educational, Scientific and Cultural Organization, UNESCO (2016). Strategy for technical and vocational education and training (TVET) (2016-2021)

Xing, B., \& Marwala, T. (2017). Implications of the fourth industrial age for higher education. The Thinker Issue 73 Third Quarter 2017

Zhan, Y., Li, L. J., Miao, L. Y., \& Li, Y. L. (2021). Marked theme analysis and its implications in academic paper writing. In Computational Social Science (pp. 442-445). CRC Press 